\title{
Introduction to the Special Issue on Cancer Immunotherapy
}

\author{
Shuen-Kuei Liao',2 \\ ${ }^{1}$ The PhD Program of Cancer Biology and Drug Discovery, Taipei Medical University, Taipei 110, Taiwan, China. \\ ${ }^{2}$ Department of Research and Development, Vectorite Biomedica Inc., New Taipei City 221, Taiwan, China.
}

\begin{abstract}
Correspondence to: Prof. Shuen-Kuei Liao, The PhD Program of Cancer Biology and Drug Discovery, Taipei Medical University, Taipei 110, Taiwan, China. E-mail: liaosk@h.tmu.edu.tw
\end{abstract}

How to cite this article: Liao SK. Introduction to the Special Issue on Cancer Immunotherapy. J Cancer Metastasis Treat 2017;3:217.

Article history: Received: 2 Oct 2017 Accepted: 18 Oct $2017 \quad$ Published: 31 Oct 2017

The biotechnology revolution started in early 1970 s following advances in molecular biology, specifically: (1) sophisticated methodologies for manipulating DNA in mammalian cells; (2) hybridoma technology for the generation of preselected monoclonal antibodies; (3) genomic and recombinant DNA technology that allowed the production of large quantities of specific proteins; and (4) improved understanding of cancer immunology. In the 1980s, we further witnessed another wave of technological revolution which includes our ability to molecularly clone many growth factors, cytokines and immunogenic molecules, and to discover immune checkpoint molecules such as cytotoxic T-lymphocyte antigen 4, programmed death 1 and programmed death ligand- 1 and their inhibitors, to develop various vaccines (dendritic cells, personalized human leukocyte antigen-binding peptides and RNA mutanomes), and to expand and/or genetically modify effector cells for adoptive cell based immunotherapy, such as chimeric antigen receptor T-cell therapy. There are major scientific, clinical and regulatory hurdles that still need to be overcome to bring the full potential clinical benefits of immunotherapy to cancer patients, particularly when an individualized approach is under consideration. The next 20 years should be very exciting period to the development of this field.
As Guest Editor of this special issue, I would like to express my sincere thanks to those who have contributed a series of articles to the issue, each representing either a commentary, original article, or review. I was so pleased that the birth of this issue which was finally turned into reality. Without the sustained enthusiasm and persistence of all the contributors and editorial staff, the completion of this issue would not have been possible.

\section{DECLARATIONS}

\section{Authors' contributions}

S.K. Liao contributed solely to the paper.

\section{Financial support and sponsorship None.}

\section{Conflicts of interest}

There are no conflicts of interest.

\section{Patient consent}

Not applicable.

\section{Ethics approval \\ Not applicable.}

